\title{
oxLDL induces injury and defenestration of human liver sinusoidal endothelial cells via LOX1
}

\author{
Qi Zhang ${ }^{1, *}$, Jing Liu ${ }^{2, *}$, Jia Liu ${ }^{2}$, Wenhui Huang ${ }^{2}$, Limin $\operatorname{Tian}^{2}$, Jinxing Quan ${ }^{2}$, \\ Yunfang Wang ${ }^{2}$ and Ruilan Niu ${ }^{1}$ \\ ${ }^{1}$ The First Clinical College of Lanzhou University, 730000 Lanzhou, Gansu, China \\ ${ }^{2}$ Department of Endocrinology, Gansu Provincial Hospital, 204 West Donggang Road, \\ 730000 Lanzhou, Gansu, China \\ *(Q Zhang and J Liu contributed equally to this work)
}

Correspondence should be addressed

to J Liu

Email

liujingwelcome@126.com

\begin{abstract}
Non-alcoholic fatty liver disease is associated with hepatic microangiopathy and liver inflammation caused by type 2 diabetes mellitus. Oxidised LDL (oxLDL) is involved in proinflammatory and cytotoxic events in various microcirculatory systems. The lectin-like oxLDL receptor 1 (LOX1) plays a crucial role in oxLDL-induced pathological transformation. However, the underlying mechanism of oxLDL's effects on liver microcirculation disturbances remains unclear. In this study, we investigated the effects of oxLDL on LOX1 (OLR1) expression and function, as well as on the fenestration features of human liver sinusoidal endothelial cells (HLSECS) in vitro. Primary HLSECs were obtained and cultured. The cells were treated with various concentrations of $\operatorname{oxLDL}(25,50,100$ and $200 \mu \mathrm{g} / \mathrm{ml})$, and the cytotoxicity and expression of LOX1 were examined. Furthermore, LOX1 knockdown was performed using siRNA technology, and the changes in intracellular reactive oxygen species (ROS), NFKB, p65, (p65), endothelin 1 (ET1 (EDN1)), eNOS (NOS3) and caveolin 1 (CAV1) levels were measured. Cells were treated with $100 \mu \mathrm{g} / \mathrm{ml}$ oxLDL, and the fenestra morphology was visualised using scanning electron microscopy. oxLDL significantly increased LOX1 expression at both the mRNA and protein levels in HLSECs in a dose- and time-dependent manner. oxLDL stimulation increased ROS generation and NFKB activation, upregulated ET1 and caveolin 1 expression, downregulated eNOS expression and reduced the fenestra diameter and porosity. All of these oxLDLmediated effects were inhibited after $L O X 1$ knockdown. These results reveal a mechanism by which oxLDL stimulates the production of LOX1 through the ROS/NFKB signalling pathway and by which LOX1 mediates oxLDL-induced endothelial injury and the defenestration of HLSECs.
\end{abstract}

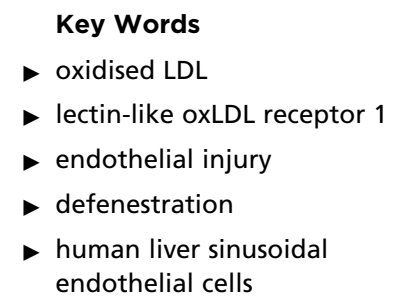

Journal of Molecular Endocrinology (2014) 53, 281-293

\section{Introduction}

Type 2 diabetes mellitus (T2DM) is potentially complicated by hepatic microangiopathy and liver inflammation (Hudacko et al. 2009) and is an independent risk factor for the formation and development of non-alcoholic fatty liver disease (NAFLD; Krishnan et al. 2013). Metabolic syndrome plays a major role in the pathogenesis of both NAFLD and T2DM (El-Serag et al. 2004). NAFLD is commonly observed in adults and adolescents with T2DM (Lv et al. 2013). Cross-sectional studies have revealed that the prevalence of NAFLD in patients with 
T2DM ranges from 42.1 to $75.2 \%$ in China (Zhou et al. 2007). However, the cause-effect relationship between these conditions is complex and difficult to decipher.

NAFLD is associated with hepatic sinusoid microcirculation (Farrell et al. 2008). Liver sinusoidal endothelial cells (LSECs) play important roles in regulating hepatic sinus function. LSECs line the capillaries of the microvasculature and possess fenestrae that facilitate filtration between the liver parenchyma and sinusoids by serving as a selectively permeable barrier (Braet et al. 1995, Braet \& Wisse 2002). Results have indicated that NAFLD is associated with dysfunction of LSECs (Braet et al. 2002). Sinusoidal endothelial fenestrae, which represent complete pores in LSECs, play important roles in liver physiology and disease. Alterations in LSEC fenestration have implications for liver function, including lipoprotein metabolism (Le Couteur et al. 2002). Preclinical studies have demonstrated that LSECs undergo defenestration as an early event that precedes liver fibrosis (Pasarín et al. 2012), and endothelin 1 (ET1) and caveolin 1 (Cav1) induce defenestration in LSECs (Yokomori et al. 2006, 2009).

Oxidised LDL (oxLDL) is formed in large quantities in the circulating blood of diabetic patients (Holvoet et al. 2008) and is a crucial risk factor for atherosclerosis (AS) and diabetic microangiopathy (Lopes-Virella et al. 1999, Witztum \& Steinberg 2001, Pirillo et al. 2013). oxLDL can lead to oxidative stress and an inflammatory response (Zmijewski et al. 2005). oxLDL has also been reported to facilitate the formation of more oxLDL and other proinflammatory cytokines through a vicious cycle mediated by a specific receptor known as the lectin-like oxidised LDL receptor 1 (LOX1; Mehta et al. 2006). LOX1 is one of the major scavenger receptors (SRs) responsible for binding, internalising and degrading oxLDL (Sawamura et al. 1997). LOX1 activation is associated with many pathophysiological events, including endothelial cell (EC) and vascular smooth muscle cell proliferation, alterations in cell cycle signals, apoptosis and autophagy (Zabirnyk et al. 2010, Yoshimoto et al. 2011). Accumulating evidence indicates that oxLDL binding to LOX1 increases intracellular reactive oxygen species (ROS), activates the NFкB signaling pathway, decreases intracellular nitric oxide (NO) and increases endothelin 1 (ET1), which could lead to endothelial dysfunction (Cominacini et al. 2000, Morawietz et al. 2002, Fleming et al. 2005).

oxLDL is involved in liver microcirculation disturbance and NAFLD (Oteiza et al. 2011, Walenbergh et al. 2013). oxLDL can activate hepatic Kupffer and stellate cells, trigger inflammation and fibrogenesis and induce sinusoidal endothelial dysfunction (Dorman et al. 2006,
Li et al. 2011). Atherogenic blood-borne oxLDL is primarily removed by cells lining the liver sinusoids (McCuskey 2006). LSECs play an important role in the blood clearance of oxLDL (Li et al. 2011). Various SRs can bind to and/or mediate endocytosis of oxLDL in LSECs (Steinberg 1997). We have previously demonstrated that LOX1 is present in LSECs. However, the role of LOX1 in oxLDL-mediated LSEC dysfunction has not been specifically investigated. In addition, whether changes in the fenestration of LSECs are the result of oxLDL binding to LOX1 is largely unknown.

In this study, we explored models of oxLDL-induced injury and LOX1 (OLR1) gene knockdown in human LSECs (HLSECs) to investigate the effects of oxLDL on endothelium function and the fenestration characteristics of HLSECs in vitro.

\section{Materials and methods}

\section{Reagents}

DMEM and foetal bovine serum (FBS) were purchased from Gibco-BRL (Gibco). The NO assay kit was purchased from Nanjing Jiancheng Bioengineering Institute (China). The primer pairs for GAPDH, LOX1, ET1 (EDN1), endothelial nitric oxide synthase (eNOS (NOS3)) and CAV1 were synthesised by TaKaRa Biotechnology Co., Ltd. (Dalian, China). TRIzol reagent, RNase inhibitor, LOX1 siRNA vector, Xfect transfection reagent and the RT-PCR kit were purchased from TaKaRa Bio, Inc. Rabbit antibodies to LOX1, CD31, von Willebrand factor (vWF), ET1, eNOS,

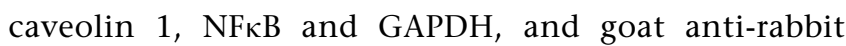
HRP-conjugated secondary antibodies were purchased from Abcam (Xinjie, Hong Kong, China) Ltd; $2^{\prime}, 7^{\prime}$-dichlorofluorescein diacetate (DCFH-DA) was obtained from Invitrogen. OxLDL was purchased from Peking UnionBiology Co., Ltd (Beijing, China). All other chemicals of analytical grade were purchased from commercial suppliers.

\section{Primary human LSEC isolation, culture and identification}

Human liver tissue was obtained from a single 53-year-old Chinese woman undergoing resection for liver cysts under sterile conditions. Informed consent was obtained from the patient and this study was approved by the ethics research committee of The First Clinical College of Lanzhou University. HLSECs were isolated from $25 \mathrm{~g}$ of human liver tissue as described previously (Daneker et al. 1998). HLSECs were cultured in DMEM supplemented with 10\% (v/v) FBS (Gibco), penicillin, streptomycin and glutamine $(100 \mathrm{U} / \mathrm{ml}$,

Published by Bioscientifica Ltd. 
100 and $292 \mathrm{mg} / \mathrm{ml}$ respectively), as well as hepatocyte growth factor and vascular endothelial growth factor (both $10 \mathrm{ng} / \mathrm{ml}$ ) under standard cell culture conditions (humidified atmosphere with $5 \% \mathrm{CO}_{2}$ at $37^{\circ} \mathrm{C}$ ). Cells were identified using an anti-CD31 antibody via immunocytochemistry and characteristic morphology in culture. Cells were cultured to confluence and were used in all experiments.

\section{Experimental protocol}

First, to investigate the effects of oxLDL on LOX1 expression in HLSECs, the cells were treated with oxLDL $(25,50,100$ or $200 \mu \mathrm{g} / \mathrm{ml})$ for 12,24 or $48 \mathrm{~h}$. Secondly, to further examine the role of LOX1 in oxLDL-induced functional injury of HLSECs, LOX1 expression was silenced. Cells were successfully transfected with LOX1 siRNA or pretreated with $250 \mu \mathrm{g} / \mathrm{ml}$ polyinosinic-cytidylic acid (PCA, a LOX1 inhibitor). The cells were divided into four experimental groups (the control, LOX1 siRNA, scrambled siRNA (control siRNA) and LOX1 inhibitor groups) and exposed to oxLDL $(100 \mu \mathrm{g} / \mathrm{ml})$ for $24 \mathrm{~h}$. The levels of LOX1, ROS, p65, eNOS, ET1, CAV1 and GAPDH were then determined; the characteristics of fenestration were simultaneously detected.

\section{Cell viability measurement}

Cells were seeded at a density of $5 \times 10^{4}$ cells $/ \mathrm{ml}$ in 96-well plates with various concentrations $(25,50,100$ and $200 \mu \mathrm{g} / \mathrm{ml}$ ) of oxLDL for $6,12,24$ or $48 \mathrm{~h}$, and the cell viability was measured using the MTT assay. Briefly, the culture supernatant was removed at the indicated time points after the treatment, and the cells were washed with PBS and incubated with MTT $(5 \mathrm{mg} / \mathrm{ml})$ in the culture medium at $37^{\circ} \mathrm{C}$ for an additional $3 \mathrm{~h}$. After MTT removal, the coloured formazan was dissolved in $100 \mu \mathrm{l}$ DMSO. The absorption values were measured at a wavelength of $490 \mathrm{~nm}$ using a Thermo Scientific Microplate Reader (Multiskan Spectrum, Thermo Labsystems, Philadelphia, PA, USA). The viability of HLSECs in each well is presented as a percentage of that of control cells.

\section{Designing the LOX1 siRNA sequence and constructing the LOX1 silencing plasmid}

For LOX1 knockdown, LOX1 siRNAs were designed based on human LOX1 cDNA. The mRNA sequences of human LOX1 were retrieved from GenBank (ID: NM_002543.3). The interference sequences were designed using the siRNA Design Support System R5: target sense sequence,
Table 1 Designed shRNA oligonucleotide sequence for LOX1 SiRNA

\begin{tabular}{ccc}
\hline $\begin{array}{c}\text { Top } \\
\text { strand }\end{array}$ & $\begin{array}{c}\text { sATCCCCCTTGCTCGGAAGCTGAATGAGAATTCAA- } \\
\text { GAGATTCTCA TTCAGCTTCCGAGCAAGGGTTTTTTG } \\
\begin{array}{c}\text { Bottom } \\
\text { strand }\end{array}\end{array}$ \\
$\begin{array}{c}\text { AATTCAAAAAACCCTTGCTCGGAAGCTGAATGA- } \\
\text { GAATCTCTTGAA TTCTCATTCAGCTTCCGAG- }\end{array}$ \\
\hline
\end{tabular}

5'-CCCTTGCTCGGAAGCTGAATGAGAA-3'; target antisense sequence, 5'-TTCTCATTCAGCTTCCGAGCAAGGG-3'. Two complementary oligonucleotides (a top strand and a bottom strand) were synthesised (Table 1). Each oligonucleotide was composed of a target sequence, the hairpin loop TTCAAGAGA, the terminator sequence TTTTTT and restriction sites (BamHI/EcoRI) added at both ends of the sequences. The complementary oligonucleotides were annealed, and the pSIREN-RetroQ-DsRed-Express vector was linearised by BamHI/EcoRI enzyme cleavage. The annealed oligonucleotide was ligated into pSIRENRetroQ-DsRed-Express using $\mathrm{T}_{4}$ DNA ligase. The connected product (pSIREN-RetroQ-DsRed-Express-LOX1 shRNA) was transformed into JM109 competent cells (code no. D9052) using the heat shock method. Subsequently, positive clones were screened, and plasmids were extracted for PCR identification and sequencing identification. Similarly, a control plasmid was constructed by randomising the shRNA sequence (5'-GGAGAGCATCTCATTCGATGCAGAC-3').

\section{Cell transfection}

Cells were seeded into 6-well plates. When confluent, cells were transfected with pSIREN-RetroQ-DsRed-Express-LOX1 shRNA ( $7.5 \mu \mathrm{g})$ or control plasmid (scrambled siRNA) using Xfect transfection reagent (TaKaRa) according to the manufacturer's instructions. The transfection efficiency was monitored by fluorescence intensity and LOX1 expression levels. A transfection rate above $70 \%$ was used for the other experiments. The cell phenotype and characteristics were evaluated after successful transfection.

\section{Immunofluorescence}

The cells were grown in 4-well chamber slides, fixed, quenched, blocked and incubated with an antibody against vWF (1:500, Abcam), or CD31 (1:500, Abcam) overnight at $4{ }^{\circ} \mathrm{C}$. Fluorescently tagged secondary antibodies were used at 1:1000 dilution. Nuclear counterstaining was performed

Published by Bioscientifica Ltd 
with DAPI. Cells were mounted and imaged by confocal microscopy (LEXT OLS4000).

\section{Measurement of intracellular ROS}

Intracellular ROS was measured using the fluorescent signal $\mathrm{H}_{2}$ DCF-DA. Cells cultured in 6-well plates were incubated with $100 \mu \mathrm{g} / \mathrm{ml}$ oxLDL. Then, the cells were harvested after the target time had been reached and incubated with $10 \mu \mathrm{mol} / \mathrm{l}$ DCFH-DA for $30 \mathrm{~min}$ at $37^{\circ} \mathrm{C}$. DCFH-DA is converted by intracellular esterases to $\mathrm{DCFH}$, which is oxidised into the high-fluorescence dichlorofluorescein (DCF) in the presence of a proper oxidant. HLSECs were washed with ice-cold PBS three times and placed in the dark. Subsequently, the DCF fluorescence was measured by flow cytometry at 488 and $525 \mathrm{~nm}$. The results were analysed using the Cell Quest software.

\section{Quantitative RT-PCR}

Total RNA was extracted with TRIzol following the manufacturer's instructions. RNA concentrations were determined using a spectrophotometer (Beckman Instruments, Fullerton, CA, USA). Approximately $2 \mu \mathrm{g}$ RNA was reverse transcribed to cDNA using the Prime Script RT reagent kit. Quantitative RT-PCR (qRT-PCR) assays were performed using the LightCycler Real-Time PCR System (Roche 480). Samples were denatured at $95^{\circ} \mathrm{C}$ for $30 \mathrm{~s}$ followed by 40 PCR cycles of $95^{\circ} \mathrm{C}$ for $5 \mathrm{~s}, 60^{\circ} \mathrm{C}$ for $30 \mathrm{~s}$ and $72{ }^{\circ} \mathrm{C}$ for $60 \mathrm{~s}$. A melting curve was used to confirm the formation of the intended PCR products. The results are expressed as the fold difference relative to the level of GAPDH using the $2^{-\triangle \Delta C T}$ method. Each reaction was performed in triplicate. The LOX1 (NM_002543.3) primers were as follows: forward, 5'-AGCAAATGGAACTTCACCACCAG-3'; reserve, 5'-CTTGGCATCCAAAGACAAGCAC-3'. GAPDH (NM_002046.2) was used as an endogenous control with the following primers: forward, $5^{\prime}$-CCACCCATGGCAAATTCCATGGCA-3'; reverse, 5'-TCTAGACGGCAGGTCAGGTCCACC-3'.

\section{Western blot analysis}

Cells were lysed for $30 \mathrm{~min}$ at $4{ }^{\circ} \mathrm{C}$ in lysis buffer. The extracted total protein concentrations were measured using the bicinchoninic acid reagent. Equal amounts of lysate proteins were loaded and separated by SDS-PAGE and transferred onto polyvinylidene fluoride membranes. After incubation in a blocking solution (5\% non-fat milk, Sigma), the membranes were immunoblotted with primary antiNFKB (phos-p65) (1:1500), anti-LOX1 (1:2000, Abcam), antieNOS (1:2000), anti-ET1 (1:2000), anti-caveolin 1 (1:2000), or anti-GAPDH (1:2500) overnight at $4{ }^{\circ} \mathrm{C}$. Membranes were washed and then incubated in a 1:3000 dilution of the specific secondary antibodies for $1.5 \mathrm{~h}$ at room temperature, and the membranes were washed. Following enhanced chemiluminescence development, the exposed film was later developed. The films were scanned using Image Quant 350 (GE Healthcare, Little Chalfont, Buckinghamshire UK), and the relative densities of protein bands were analysed using the Image J software (National Institutes of Health, Bethesda, MD, USA). The density of each protein band was normalised to that of GAPDH.

\section{Scanning electron microscopy}

LSECs cultured on glass coverslips were fixed in 1.2\% glutaraldehyde buffered with $1 \mathrm{M}$ cacodylate buffer (pH 7.4) for $1 \mathrm{~h}$ at $4{ }^{\circ} \mathrm{C}$ and post-fixed with $1 \%$ osmium tetroxide in cacodylate buffer ( $\mathrm{pH} 7.4)$ for $1 \mathrm{~h}$ at $4{ }^{\circ} \mathrm{C}$. After dehydration in a graded series of ethanol solutions, the cultured cells were dried in a critical point apparatus (HCR-2, Hitachi) and coated with gold in a vacuum coating unit. The fenestrae were observed for each experimental variable under a scanning electron microscope (SU8010, Hitachi) at a $15-\mathrm{kV}$ acceleration voltage and $\times 20000$ magnification.

\section{Statistical analysis}

All data are expressed as mean \pm s.D. from at least three independent experiments each performed in triplicate. All data were analysed by one-way ANOVA followed by the Bonferroni comparison using SPSS 17.0. A $P$ value of $<0.05$ was considered statistically significant.

\section{Results}

\section{Isolated HLSECs express CD31 in culture}

We observed that cultured primary HLSECs were polygonal or fusiform with a cobblestone appearance, as demonstrated by inverted microscopy after $2-4$ days in culture (Fig. 1A). To confirm the identity of HLSECs, we assessed the expression of CD31 in HLSECs, after culturing the cells for $48 \mathrm{~h}$, using immunofluorescence (IF) staining and nuclear counterstaining. We found that the cells expressed CD31, as indicated by green and blue fluorescence under an inverted fluorescence microscope (Fig. 1B).

Published by Bioscientifica Ltd 

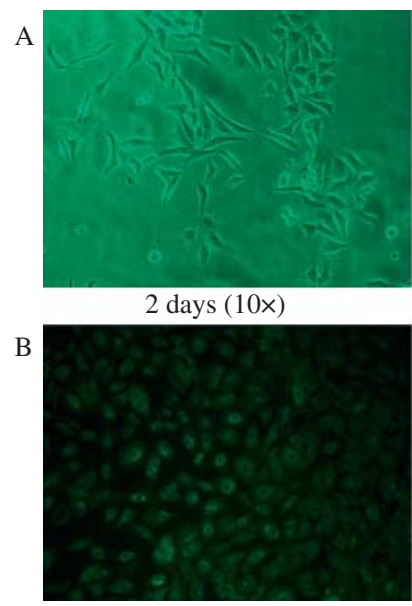

CD31

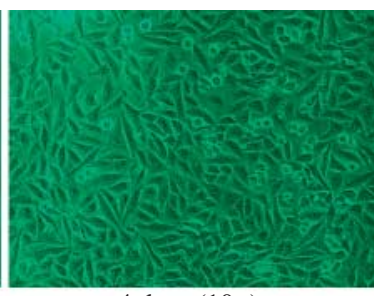

4 days $(10 \times)$

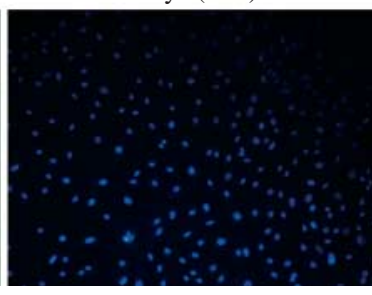

CD31 with DAPI

\section{Figure 1}

Characterisation and identification of isolated human liver sinusoidal endothelial cells (HLSECS) in vitro. (A) HLSECs were isolated from human liver and cultured. HLSEC morphology was assessed on day 2 or 4 of culture by inverted microscopy. The cells grew by static adherence, and the shape of the cells was fusiform or polygon, resembling cobblestones. (B) HLSECS isolated from human liver were cultured for 2 days and stained with anti-CD31 antibodies. Fluorescence images were acquired at an original magnification of $20 \times$ (green, CD31 expression; blue, nuclear counterstaining with DAPI).

\section{oxLDL exhibits cytotoxic effects on HLSECs in vitro}

To investigate whether oxLDL is cytotoxic to HLSECs, cells were treated with $25,50,100$ or $200 \mu \mathrm{g} / \mathrm{ml}$ oxLDL for 6,12 , 24 or $48 \mathrm{~h}$ and then assessed using the MTT assay. We observed that the cell viability decreased in a doseand time-dependent manner $(P<0.05$; Fig. $2 \mathrm{~A})$, whereas the native LDL had no effect. oxLDL concentrations $>100 \mu \mathrm{g} / \mathrm{ml}$ had noticeable cytotoxic effects. Furthermore, exposure to $200 \mu \mathrm{g} / \mathrm{ml}$ oxLDL for $12 \mathrm{~h}$ caused a significant $(23.3 \%)$ decrease in cell viability; increased exposure for $48 \mathrm{~h}$ decreased the viability of HLSECs (by $42 \%$ total from time 0 ).

\section{oxLDL increased LOX1 expression in HLSECs}

To determine whether LOX1 is involved in oxLDLinduced inflammatory responses in HLSECs, we examined the effect of oxLDL on LOX1 expression. HLSECs were treated with 25, 50, 100 and $200 \mu \mathrm{g} / \mathrm{ml}$ oxLDL for 6, 12, 24 or $48 \mathrm{~h}$. Both qRT-PCR (Fig. 2B) and western blotting (Fig. 2C) results revealed that LOX1 mRNA and protein expression gradually increased in response to oxLDL. Hence, oxLDL induced LOX1 expression in a time- and dose-dependent manner. LOX1 expression peaked at $100 \mu \mathrm{g} / \mathrm{ml}$ and $24 \mathrm{~h}$ (3.1-fold vs control, $P<0.05)$; therefore, this concentration was used for all subsequent experiments.

\section{The transfected HLSECs maintain specific markers and limited fenestrae}

To confirm endothelial phenotype and characterisation of transfected HLSECs, the classic EC markers, vWF and CD31 were analysed using IF staining and nuclear counterstaining, and fenestrae were visualised using scanning electron microscopy (SEM). Compared with the isolated HLSECs, we found that transfected cells maintained similar expression of vWF and CD31 (Fig. 3A and B) and maintained limited transcytoplasmic fenestrations (Fig. 3C, arrows).

\section{LOX1 siRNA successfully suppressed $L O X 1$ mRNA and protein expressions}

To ensure the efficiency of LOX1 gene silencing, we designed three pairs of siRNA for LOX1 cDNA. After transfection, we screened for the most efficacious siRNA for LOX1 silencing using RT-PCR and western blotting. As shown in Fig. 3D, red fluorescence intensity was clearly increased relative to the control, indicating that the HLSECs had successfully been transfected with the LOX1 siRNA. The LOX1 mRNA and protein expressions were significantly decreased compared with the positive control $(100 \mu \mathrm{g} / \mathrm{ml}$ oxLDL, $P<0.05)$, and the control plasmid had no effect. The inhibition efficiencies of $L O X 1$ siRNA on mRNA and protein expressions were 77 and $74 \%$ respectively (Fig. 3E and F). Moreover, PCA, which is a LOX1 inhibitor, imparted a weak reduction in LOX1 expression compared with LOX1 siRNA treatment; the inhibition efficiencies of PCA on LOX1 mRNA and protein expressions were 21 and 32\% respectively (Fig. 3E and F).

\section{oxLDL stimulated ROS formation and NFKB activation in HLSECs through LOX1}

To confirm that LOX1 is involved in oxLDL-induced $\mathrm{ROS} / \mathrm{NF} \kappa \mathrm{B}$ activation, we investigated the influence of oxLDL $(100 \mu \mathrm{g} / \mathrm{ml})$ on ROS formation and NFKB activation in HLSECs under control conditions, LOX1 siRNA transfection and LOX1 inhibitor treatment for $24 \mathrm{~h}$. As shown in Fig. 4A, oxLDL markedly enhanced ROS formation and activated p65 in HLSECs (Fig. 4B and C). Interestingly, LOX1 silencing significantly attenuated oxLDL-induced ROS formation (Fig. 4A) and inhibited p65 expression and $\mathrm{NF} \kappa \mathrm{B}$ activation (Fig. $4 \mathrm{~B}$ and $\mathrm{C}$ )

Published by Bioscientifica Ltd. 

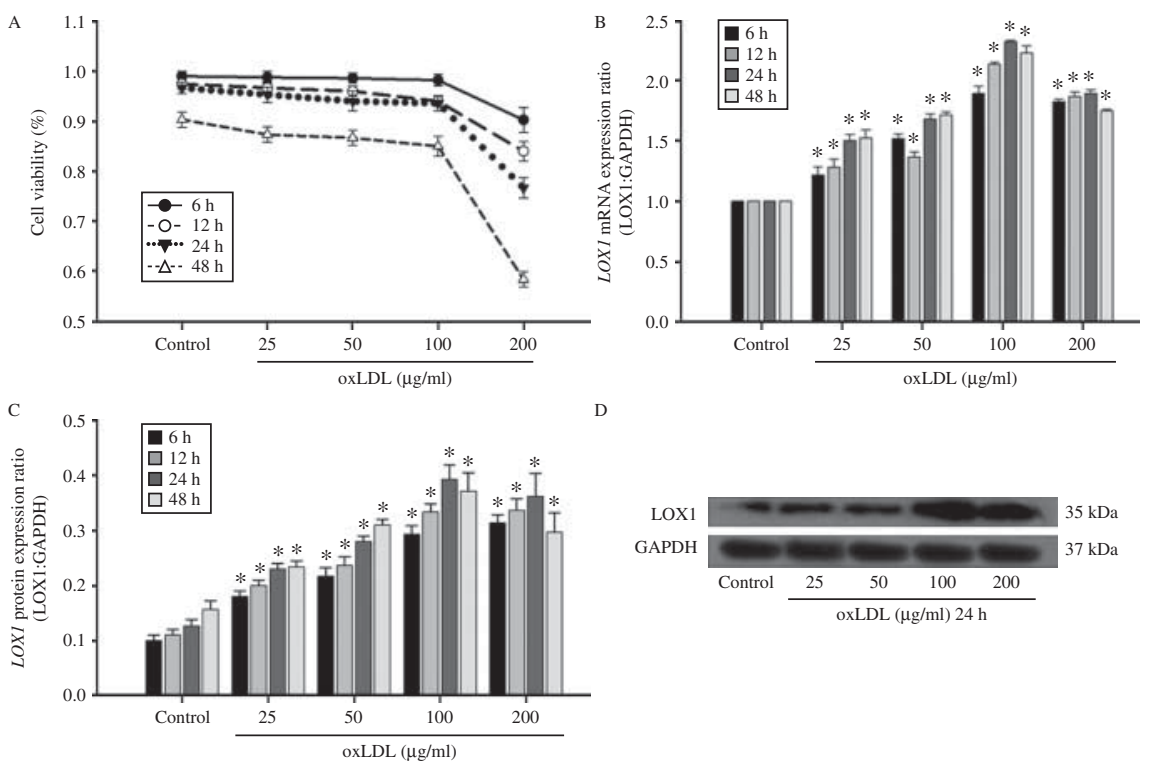

Figure 2

Effect of oxidised LDL (ox-LDL) on cytotoxicity and the expression of lectinlike oxidised LDL receptor 1 (LOX1) in cultured HLSECs. HLSECs were treated with ox-LDL $(25,50,100$ and $200 \mu \mathrm{g} / \mathrm{ml})$ for $6,12,24$ or $48 \mathrm{~h}$. (A) The effect of oxLDL on HLSEC viability (control is native LDL). (B) Quantitative

in HLSECs. PCA had similar but milder effects (Fig. 4A, B and $\mathrm{C}$ ). These results indicate that oxLDL induced marked oxidative stress and that LOX1 mediated the activation of the ROS/NFKB pathway in oxLDL-treated HLSECs.

\section{oxLDL stimulation reciprocally decreases eNOS via LOX1}

We investigated the influence of oxLDL on HLSEC eNOS expression using western blotting. As shown in Fig. 4D, eNOS expression at $24 \mathrm{~h}$ was decreased by 0.55 -fold after exposure to $100 \mu \mathrm{g} / \mathrm{ml}$ oxLDL in HLSECs compared with controls. Similarly, LOX1 silencing and LOX1 inhibition elevated oxLDL-induced eNOS expression by 45.5 and $16 \%$ respectively (Fig. 4D). Taken together, these results indicate that oxLDL downregulates eNOS expression via LOX1 in cultured HLSECs.

\section{oxLDL upregulates ET1 and caveolin 1 via LOX1 in HLSECs}

To ascertain whether LOX1 is involved in the effect of oxLDL on ET1 and caveolin 1 (CAV1), we examined the effects of oxLDL on ET1 and CAV1 expression in HLSECs. Cells were pretreated with oxLDL $(100 \mu \mathrm{g} / \mathrm{ml})$ for $24 \mathrm{~h}$. oxLDL exposure notably increased ET1 and CAV1 levels in HLSECs compared with controls $(P<0.05)$ : ET1 and CAV1 were overexpressed by 3.0- and 2.7-fold respectively (Fig. 4E and real-time PCR analysis of $L O X 1$ mRNA. The results were normalised to GAPDH mRNA levels. (c) Western blotting for LOX1 protein expression in HLSECs normalised to GAPDH (37 kDa) protein levels. All data are expressed as mean \pm s.D. from three independent experiments. ${ }^{*} P<0.05$ vs control.

F). The treatment of cells with LOX1 siRNA markedly decreased ET1 and CAV1 levels to 65 and 48\% respectively; however, PCA inhibition resulted in milder effects (Fig. 4E and $\mathrm{F}$ ). These results demonstrate that oxLDL promotes the increase in ET1 and CAV1 expression observed with oxLDL treatment and further confirm that LOX1 plays a critical role in mediating the ET1 and Cav1 response to oxLDL in HLSECs.

\section{oxLDL stimulated fenestra contraction and defenestration via LOX1}

We examined whether oxLDL interacts with the fenestrae of HLSECs. We used SEM at $5000 \times$ and $20000 \times$ magnification to observe the porosity and number of fenestrae in oxLDL $(100 \mu \mathrm{g} / \mathrm{ml})$-treated HLSECs for $24 \mathrm{~h}$. As shown in Fig. 5 and Table 2, we observed that oxLDL caused a significant decrease in the porosity, diameter and number of fenestrae compared with the control group (Fig. 5A and B, a and b, arrows), LOX1 silencing and LOX1 inhibitor treatment maintained a limited number of fenestrae and prevented fenestra contraction when HLSECs were treated with oxLDL (Fig. 5A and B, c, d, e, $\mathrm{f}, \mathrm{g}$ and $\mathrm{h}$, arrows), indicating that oxLDL induced both the contraction of fenestrae and defenestration in HLSECs and that LOX1 plays an important role in this pathway.

Published by Bioscientifica Ltd. 


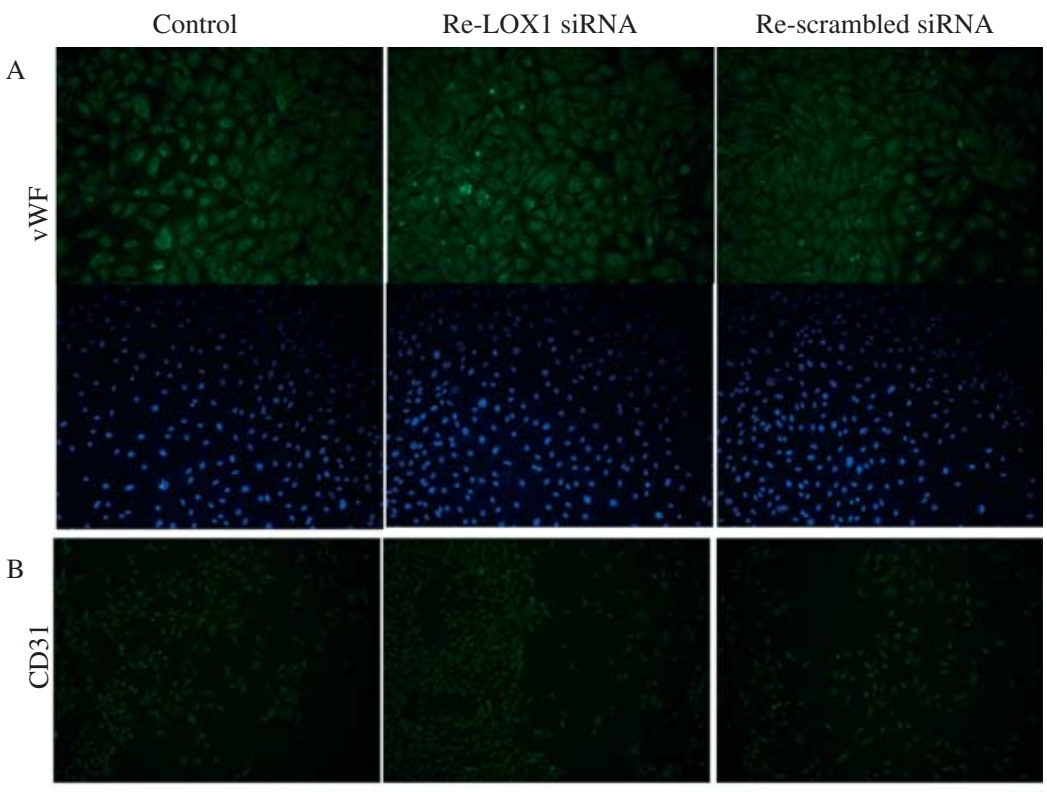

C

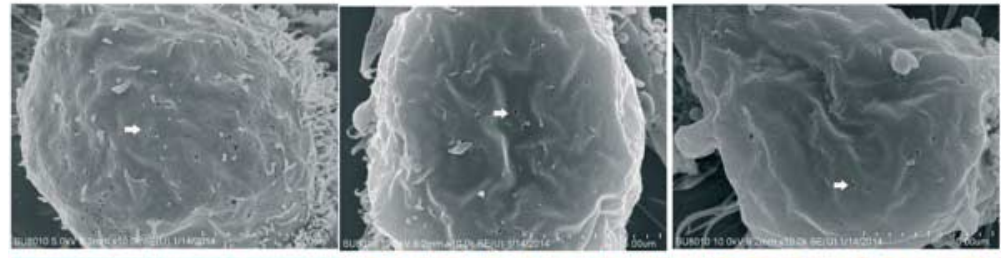

$\mathrm{D}$

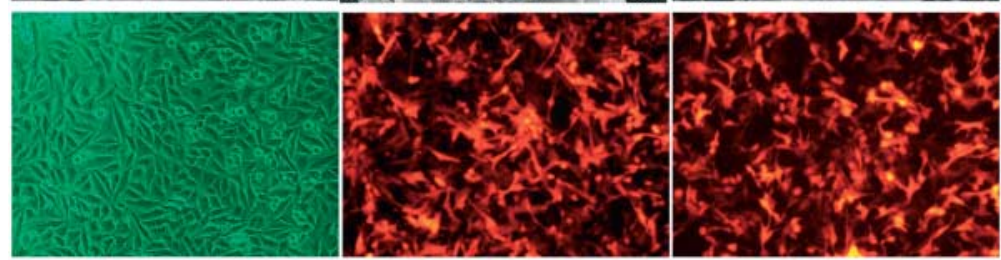

E

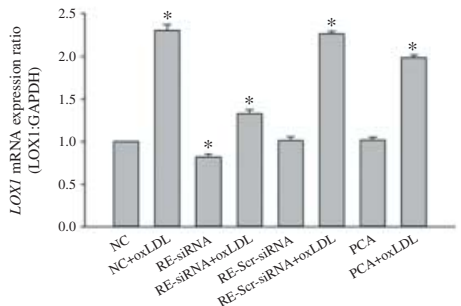

$\mathrm{F}$

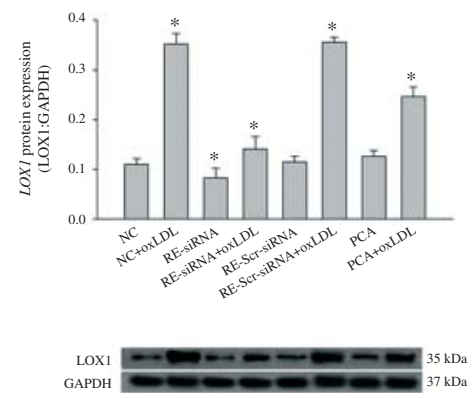

\section{Figure 3}

Characterisation of transfected HLSECS and transfection efficiency of LOX1 siRNA. HLSECs were transfected with a retrovirus LOX1 siRNA plasmid (Re-siRNA) or with a scrambled siRNA control plasmid (Re-scr-siRNA), then the specific phenotype markers and fenestrae of cells were visualised. In addition, HLSECs were treated previously with a LOX1 inhibitor (PCA $250 \mu \mathrm{g} / \mathrm{ml}$ ). All samples were treated with $100 \mu \mathrm{g} / \mathrm{ml}$ oxLDL for $24 \mathrm{~h}$. Untreated controls were run in parallel. (A) Immunofluorescent (IF) staining confirms homogeneous expression and demonstrates a cytoplasmic and plasma membrane distribution of VWF (green) with nuclear counterstaining (blue). (B) IF staining confirms homogeneous expression and demonstrates a cytoplasmic and plasma membrane distribution of CD31 (green). (C) Scanning electron microscopy (SEM) demonstrates that transfected HLSECs maintain a limited number of fenestrae (white arrows). (D) Fluorescence intensity analysis of Re-LOX1 siRNA and Re-scr-siRNA transfection. (E) Quantitative RT-PCR analysis of LOX1 mRNA in various samples normalised to GAPDH mRNA levels. (F) Western blotting was performed to assess LOX1 protein expression in various samples. GAPDH served as a loading control. ( $E$ and $F$ ) Data expressed as mean \pm s.D. from three independent experiments, $* P<0.05$ vs control.

Published by Bioscientifica Ltd. 

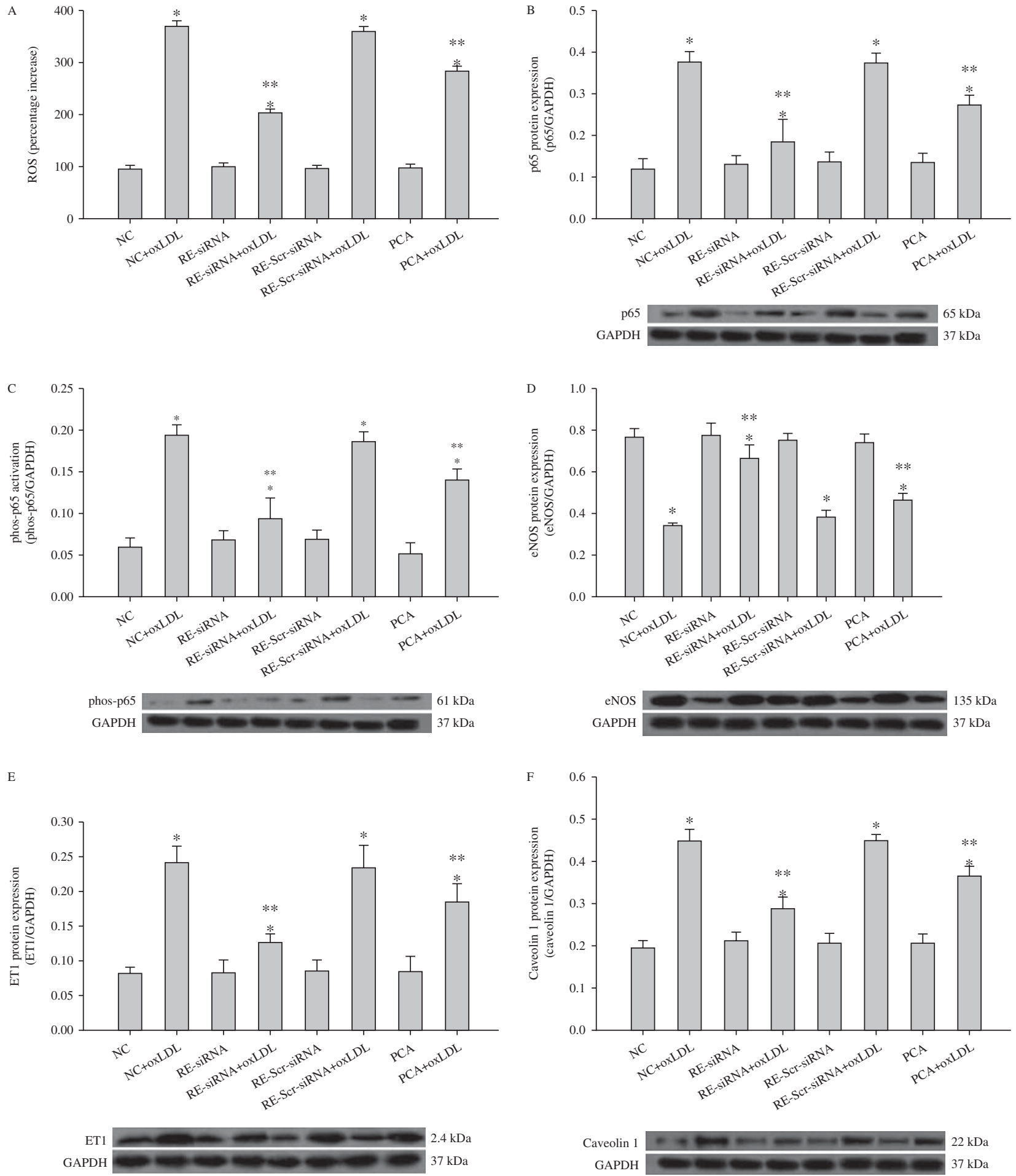

\section{Figure 4}

Role of LOX1 in oxLDL-mediated injury in cultured HLSECs. Cells were transfected with LOX1 siRNA and blocked with a LOX1 inhibitor (PCA $250 \mu \mathrm{g} / \mathrm{ml}$ ). All samples were treated with $100 \mu \mathrm{g} / \mathrm{ml}$ oxLDL for $24 \mathrm{~h}$. Untreated intact samples were run as a control in each experiment. (A) Relative ROS formation was measured as fluorescence intensity. (B) Western blotting results showing relative p65 expression. (C) Western blotting results showing

relative phos-p65 expression of NFKB activation. (D) Western blotting results showing relative eNOS expression. (E) Western blotting results showing relative ET1 expression. (F) Western blotting results showing relative Cav1 expression. (A, B, C, D, E and F) All results are expressed as mean \pm s.D. from three independent experiments, $* P<0.05$ vs control(NC), $* * P<0.05$ vs NC + oxLDL. (B, C, D, E, and F) GAPDH (37 kDa) represents the loading control.

Published by Bioscientifica Ltd. 


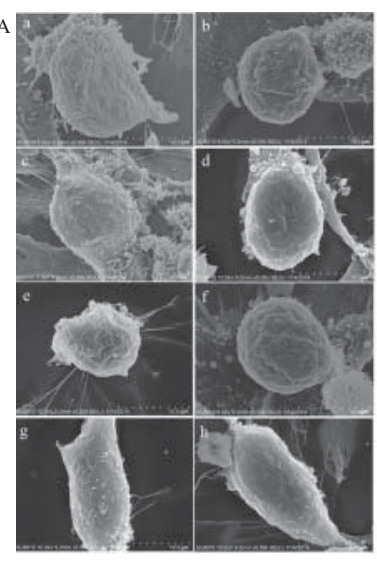

$(5000 \times)$

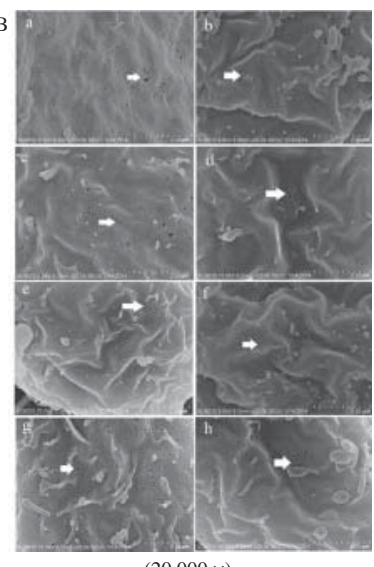

$(20000 \times)$

\section{Figure 5}

The role of LOX1 in oxLDL-mediated defenestration in cultured HLSECs. Cells were transfected with LOX1 siRNA and blocked with a LOX1 inhibitor (PCA $250 \mu \mathrm{g} / \mathrm{ml}$ ). All samples were treated with $100 \mu \mathrm{g} / \mathrm{ml}$ oxLDL for $24 \mathrm{~h}$. Untreated intact samples were used as controls. Scanning electron microscopy (SEM) images at $5000 \times(A)$ and $20000 \times(B)$ magnification of LSECs demonstrate the relative diameter and porosity of the fenestrae. (a) Fenestrae or clusters of fenestrae (sieve plates) in normal cultured HLSECs (white arrow). (b) Fenestra contraction, reduction and defenestration in $100 \mu \mathrm{g} / \mathrm{ml}$ oxLDL-treated HLSECs (white arrow). (c) Fenestrae or clusters of fenestrae (sieve plates) in HLSECs transfected with Re-LOX1 siRNA (white arrow). (d) Fenestra contraction and dispersion in $100 \mu \mathrm{g} / \mathrm{ml}$ oxLDL-treated HLSECs transfected with Re-LOX1 siRNA (white arrow). (e) Fenestrae or clusters of fenestrae (sieve plates) in HLSECs transfected with Re-scrambled siRNA (white arrow). (f) Fenestra contraction, reduction and defenestration in $100 \mu \mathrm{g} / \mathrm{ml}$ oxLDL-treated HLSECs transfected with Re-scrambled siRNA (white arrow). (g) Fenestrae or clusters of fenestrae (sieve plates) in HLSECs inhibited with PCA (white arrow). (h) Fenestra contraction and reduction in $100 \mu \mathrm{g} / \mathrm{ml}$ oxLDL-treated HLSECs inhibited with PCA (white arrow).

\section{Discussion}

Endothelial dysfunction is a major cause of diabetic microangiopathy (Cameron \& Cruickshank 2007, Renier et al. 2007), and oxidative damage is a critical step in this process (Hink et al. 2001, Hamilton \& Watts 2013). Hepatic sinusoid endothelial dysfunction is an early event implicated in the progression to NAFLD (Pasarín et al. 2012). This dysfunction is known to impair endothelium-dependent relaxation in the liver microcirculation and contribute to increased intrahepatic vascular resistance (Yokomori et al. 2012). oxLDL has been implicated as a causal factor in the pathogenesis of AS and endothelial dysfunction (LopesVirella et al. 1999, Galle et al. 2000). Evidence increasingly indicates that oxLDL has numerous deleterious effects through inducing the expression of certain surface molecules on ECs (Mertens \& Holvoet 2011), stimulating EC apoptosis, inducing ROS formation, uncoupling eNOS and impairing endothelial NO formation (Maziere et al. 1996, Cominacini et al. 2000, Fleming et al. 2005).
Responses to oxLDL in the endothelium are mediated by LOX1 (Cominacini et al. 2001).

The focus of the present article is the effect of oxLDL on LOX1 expression, tissue injury and the fenestration characteristics of HLSECs. Our results indicated for the first time, to our knowledge, that oxLDL increases LOX1 expression and induces injury through ROS formation, NFKB activation, eNOS downregulation, ET1 and CAV1 upregulation and defenestration in HLSECs. These processes are mediated via LOX1 and blocked by a LOX1directed siRNA or a LOX1 inhibitor.

LOX1 not only internalises modified lipids but also causes endothelial dysfunction, apoptosis, inflammation and smooth muscle cell proliferation, contributing to the process of atheroma formation at multiple levels (Xu et al. 2013). LOX1 has been identified as the main endothelial receptor for oxLDL (Sawamura et al. 1997). Evidence increasingly indicates that LOX1 activity promotes vascular dysfunction and AS (Pirillo et al. 2013). Through interactions with LOX1, oxLDL activates ECs and induces endothelial dysfunction and apoptosis (Mehta et al. 2006). In this study, we found that LOX1 is highly expressed in primary HLSECs upon oxLDL stimulation, and the effect of oxLDL is dose- and time-dependent in vascular ECs (Li \& Mehta 2000, Ishino et al. 2007). Results from a previous study have indicated that LOX1 expression is increased in atherosclerotic plaques when compared with normal endothelial tissue (Ishino et al. 2007), and Lox1 knockout mice exhibit markedly smaller atherosclerotic lesions (Mehta et al. 2007), indicating that LOX1 plays an important role in HLSEC dysfunction.

oxLDL is a proatherogenic lipoprotein that has been identified as a potent stimulus for vascular ROS and has been suggested to modulate gene expression in vascular cells by binding to the receptor LOX1 (Mehta et al. 2006). High levels of ROS are produced in several disease conditions, including AS, and contribute to endothelial dysfunction (Ballinger 2005, Doughan et al. 2008). ROS are involved in LDL oxidation and mediate many of its biological effects by generating more intracellular ROS through binding to LOX1. LOX1 activation can stimulate ROS generation, indicative of a positive feedback loop between ROS and LOX1. Indeed, ROS enhances LOX1 expression, and LOX1 enhances ROS production (Galle et al. 2006, Chen et al. 2009). Our results are consistent with these findings, demonstrating that oxLDL markedly increases ROS formation. Furthermore, a LOX1-directed siRNA and PCA both inhibited oxLDLinduced ROS formation, indicating that reducing LOX1 expression might suppress ROS generation and inhibit the

Published by Bioscientifica Ltd 
Table 2 The effects of oxLDL on the fenestrae of HLSECs determined by analysis of images obtained by electron microscopy. Results are expressed as mean \pm s.D. of fields from each experiment $(n=3)$. Cells were transfected with LOX1 siRNA and blocked with a LOX1 inhibitor (PCA $250 \mu \mathrm{g} / \mathrm{ml}$ ). All samples were treated with $100 \mu \mathrm{g} / \mathrm{ml}$ oxLDL for $24 \mathrm{~h}$. Untreated intact samples were used as controls. The diameter, frequency and porosity of the fenestrae were examined by scanning electron microscopy (SEM) at $\times 5000$ or $\times 20000$ magnification. Data are expressed as mean \pm s.D. from analysis of images from each experiment ( $n=3$ for each group). The eight groups were compared by ANOVA

\begin{tabular}{|c|c|c|c|}
\hline & \multicolumn{2}{|c|}{ Normal } & $\mathbf{R e}-$ \\
\hline & - & oxLDL & - \\
\hline $\begin{array}{l}\text { Fenestration frequency } \\
\left(\text { number } / \mu \mathrm{m}^{2}\right)\end{array}$ & $6.5 \pm 0.5$ & $4.0 \pm 0.5^{*}$ & $6.3 \pm 0.5$ \\
\hline Porosity (\%) & $4.6 \pm 0.4$ & $2.7 \pm 0.3^{*}$ & $4.7 \pm 0.4$ \\
\hline $\begin{array}{l}\text { Fenestration } \\
\quad \text { diameter }(\mathrm{nm})\end{array}$ & $127 \pm 4$ & $49 \pm 2 *$ & $115 \pm 3^{\dagger}$ \\
\hline
\end{tabular}

positive feedback loop. NFאB is a relevant transcription factor for a variety of inflammatory mediators (Mohamed \& McFadden 2009). Recent evidence has indicated that the binding of oxLDL to LOX1 activates the NFkB signalling pathway and causes cell injury (Cominacini et al. 2000). Our findings indicate that NFאB is activated by oxLDL and might serve as an intermediate link in the inflammatory response that occurs during HLSEC dysfunction. Inhibition of LOX1 expression with an siRNA or an inhibitor decreased oxLDL-induced ROS formation and NFKB activation. Our results indicate that oxLDL-induced NFאB activation is at least partially mediated via LOX1 in HLSECs.

$\mathrm{NO}$, a potent vasodilatory substance, is generated from $\mathrm{L}$-arginine by eNOS (Channon 2004). ET1 is a potent vasoconstrictor peptide, and both ET1 and NO play pivotal roles in vascular homoeostasis (Kauser et al. 2000). ET1 and NO work as negative feedback signals for each other (Li et al. 2003, Oishi et al. 2006, Kohan et al. 2011). The reduced activation of eNOS is a characteristic of vascular endothelial dysfunction (Wohlfart et al. 2008), and ET1 could promote early events leading to endothelial dysfunction and AS (Rautureau \& Schiffrin 2012). Diminished production of $\mathrm{NO}$ and aggravated release of ET1 are thought to be key initiators of endothelial injury (Little et al. 2008, Li et al. 2011). oxLDL causes abnormalities in endothelial function by decreasing eNOS activity in ECs (Cominacini et al. 2001, Zhou et al. 2013) and further promotes a proatherosclerotic 'vicious circle' by augmenting ET1 release and superoxide anion formation in the vessel wall (Morawietz et al. 2002, Kalani 2008). It is therefore possible that ET1 contributes to endothelial dysfunction both directly, through its vasoconstrictor effects, and indirectly, through inhibition of NO production. Liver sinusoidal endothelial dysfunction with decreased intrahepatic NO production has long been considered a relevant pathogenic factor in the progression of liver cirrhosis (Fraser et al. 2012). We demonstrated that oxLDL increases ET1 expression and decreases eNOS expression in HLSECs and thereby impairs endothelial dysfunction. Similarly, our findings indicate that LOX1 gene silencing suppresses ET1 expression and increases eNOS expression in cultured HLSECs. These findings further support the importance of LOX1 in oxLDLstimulated dysfunction in HLSECs.

CAV1 is a membrane protein involved in the maintenance of fenestrae (Braet et al. 2003) and has been observed in the fenestrae of isolated LSECs (Ogi et al. 2003). CAV1 potentially plays an important positive role in the regulation of LSEC tubular formation (Yokomori et al. 2009). Recent studies demonstrate that CAV1 expression increases oxLDL uptake by hepatic cells and mediates oxLDL endocytosis and transcytosis by ECs (Truong et al. 2009, Sun et al. 2010). Furthermore, oxLDL upregulates CAV1 expression and downregulates eNOS expression at the mRNA and protein levels in HUVECs (Ma et al. 2012). oxLDL upregulates CAV1 expression in macrophages via the MAPK/NFкB pathway (Wu et al. 2009). Consistent with these reports, we found that oxLDL upregulated CAV1 expression in HLSECs; this effect was inhibited by blocking LOX1 using an siRNA or PCA. Thus, our results indicated that LOX1 is involved in oxLDLinduced CAV1 expression in HLSECs.

Defenestration of LSECs influences the hepatic clearance of medications owing to the impaired transfer of protein-bound substrates or dissolved substrates through the fenestrations (Braet et al. 2003). LSEC defenestration occurs in models of pathological liver states, such as cirrhosis and type 1 diabetic liver (Fraser et al. 2012).

Published by Bioscientifica Ltd. 
ET1, LPS and ethanol induce defenestration in LSECs (Dobbs et al. 1994, Wang et al. 2005, Yokomori et al. 2006). Thrombospondin 1 can cause defenestration of LSECs through the Rho-Rho kinase-myosin pathway (Venkatraman \& Tucker-Kellogg 2013), and Cav1 regulates endothelial capillary-like tubular formation and fenestra contraction in sinusoidal ECs (Yokomori et al. 2009). Our findings indicate that expression of both ET1 and CAV1 is upregulated in oxLDL-treated HLSECs, which may be the cause of fenestra contraction and defenestration. Analysis of our scanning EM results indicated that the diameter, number and porosity of the fenestrae in oxLDLtreated HLSECs were reduced or absent. Furthermore, inhibiting LOX1 using an siRNA or an inhibitor suppressed defenestration. These associations support the conclusion that LOX1 is involved in oxLDL-induced defenestration of HLSECs. However, the mechanism by which LOX1, ET1 and caveolin 1 influence each other is unknown and requires further investigation.

In conclusion, our results demonstrate that oxLDL induces dysfunction and defenestration of HLSECs through LOX1 activation. In contrast, gene silencing or blockade of $L O X 1$ significantly reduces those effects. These findings indicate that LOX1 mediates oxLDL-induced injury and defenestration of HLSECs. Furthermore, these results could provide us with insights into NAFLD, which is associated with LOX1 upregulation in HLSECs in T2DM.

\section{Declaration of interest}

The authors declare that there is no conflict of interest that could be perceived as prejudicing the impartiality of the research reported.

\section{Funding}

This work was supported by the National Natural Science Foundation of China (grant numbers 81160108,81360131 and 81260136) and the Natural Science Foundation of Gansu Province (grant number 1208RJZA113).

\section{Acknowledgements}

The authors thank the teachers in the central laboratory of the First Hospital of Lanzhou University for their technical assistance.

\section{References}

Ballinger SW 2005 Mitochondrial dysfunction in cardiovascular disease. Free Radical Biology \& Medicine 38 1278-1295. (doi:10.1016/j.freeradbiomed.2005.02.014)

Braet F \& Wisse E 2002 Structural and functional aspects of liver sinusoidal endothelial cell fenestrae: a review. Comparative Hepatology 1 1. (doi:10. 1186/1476-5926-1-1)
Braet F, De Zanger R, Baekeland M, Crabbé E, Van Der Smissen P \& Wisse E 1995 Structure and dynamics of the fenestrae-associated cytoskeleton of rat liver sinusoidal endothelial cells. Hepatology 21 180-189. (doi:10. 1016/0270-9139(95)90427-1)

Braet F, Vanbesien J, De Zanger R \& Wisse E 2002 Ageing of the liver sieve and pseudocapillarisation. Lancet 360 1171-1172. (doi:10.1016/S01406736(02)11214-1)

Braet F, Muller M, Vekemans K, Wisse E \& Le Couteur DG 2003 Antimycin A-induced defenestration in rat hepatic sinusoidal endothelial cells. Hepatology 38 394-402. (doi:10.1053/jhep.2003.50347)

Cameron JD \& Cruickshank JK 2007 Glucose, insulin, diabetes and mechanisms of arterial dysfunction. Clinical and Experimental Pharmacology \& Physiology 34 677-682. (doi:10.1111/j.1440-1681.2007.04659.x)

Channon KM 2004 Tetrahydrobiopterin: regulator of endothelial nitric oxide synthase in vascular disease. Trends in Cardiovascular Medicine 14 323-327. (doi:10.1016/j.tcm.2004.10.003)

Chen WL, Qian Y, Meng WF, Pang JY, Lin YC, Guan YY, Chen SP, Liu J, Pei Z \& Wang GL 2009 A novel marine compound xyloketal B protects against oxidized LDL-induced cell injury in vitro. Biochemical Pharmacology 78 941-950. (doi:10.1016/j.bcp.2009.05.029)

Cominacini L, Pasini AF, Garbin U, Davoli A, Tosetti ML, Campagnola M, Rigoni A, Pastorino AM, Lo Cascio V \& Sawamura T 2000 Oxidized low density lipoprotein (ox-LDL) binding to ox-LDL receptor-1 in endothelial cells induces the activation of NF- $\kappa \mathrm{B}$ through an increased production of intracellular reactive oxygen species. Journal of Biological Chemistry 275 12633-12638. (doi:10.1074/jbc.275.17.12633)

Cominacini L, Rigoni A, Pasini AF, Garbin U, Davoli A, Campagnola M, Pastorino AM, Lo Cascio U \& Sawamura T 2001 The binding of oxidized lowdensity lipoprotein (oxLDL) to ox-LDL receptor-1 in endothelial cells reduces the intracellular concentration of nitric oxide through an increased production of superoxide. Journal of Biological Chemistry 276 13750-13755. (doi:10.1074/jbc.M010612200)

Daneker GW, Lund SA, Caughman SW, Swerlick RA, Fischer AH, Staley CA \& Ades EW 1998 Culture and characterization of sinusoidal endothelial cells isolated from human liver. In Vitro Cellular \& Developmental Biology. Animal 34 370-377. (doi:10.1007/s11626-998-0018-9)

Dobbs BR, Rogers GW, Xing HY \& Fraser R 1994 Endotoxin-induced defenestration of the hepatic sinusoidal endothelium: a factor in the pathogenesis of cirrhosis? Liver 14 230-233. (doi:10.1111/j.1600-0676. 1994.tb00080.x)

Dorman RB, Wunder C, Saba H, Shoemaker JL, MacMillan-Crow LA \& Brock RW 2006 NAD(P)H oxidase contributes to the progression of remote hepatic parenchymal injury and endothelial dysfunction, but not microvascular perfusion deficits. American Journal of Physiology. Gastrointestinal and Liver Physiology 290 G1025-G1032. (doi:10.1152/ ajpgi.00246.2005)

Doughan AK, Harrison DG \& Dikalov SI 2008 Molecular mechanisms of angiotensin II-mediated mitochondrial dysfunction: linking mitochondrial oxidative damage and vascular endothelial dysfunction. Circulation Research 102 488-496. (doi:10.1161/CIRCRESAHA.107.162800)

El-Serag HB, Tran T \& Everhart JE 2004 Diabetes increases the risk of chronic liver disease and hepatocellular carcinoma. Gastroenterology 126 460-468. (doi:10.1053/j.gastro.2003.10.065)

Farrell GC, Teoh NC \& McCuskey RS 2008 Hepatic microcirculation in fatty liver disease. Anatomical Record 291 684-692. (doi:10.1002/ar.20715)

Fleming I, Mohamed A, Galle J, Turchanowa L, Brandes RP, Fisslthaler B \& Busse R 2005 Oxidized low-density lipoprotein increases superoxide production by endothelial nitric oxide synthase by inhibiting PKC $\alpha$. Cardiovascular Research 65 897-906. (doi:10.1016/j.cardiores.2004.11.003)

Fraser R, Cogger VC, Dobbs B, Jamieson H, Warren A, Hilmer SN \& Le Couteur DG 2012 The liver sieve and atherosclerosis. Pathology 44 181-186. (doi:10.1097/PAT.0b013e328351bcc8)

Galle J, Lehmann-Bodem C, Hubner U, Heinloth A \& Wanner C 2000 CyA and OxLDL cause endothelial dysfunction in isolated arteries through endothelin-mediated stimulation of $\mathrm{O}_{2}^{-}$formation. Nephrology, Dialysis, Transplantation 15 339-346. (doi:10.1093/ndt/15.3.339) 
Galle J, Hansen-Hagge T, Wanner C \& Seibold S 2006 Impact of oxidized low density lipoprotein on vascular cells. Atherosclerosis 185 219-226. (doi:10.1016/j.atherosclerosis.2005.10.005)

Hamilton SJ \& Watts GF 2013 Endothelial dysfunction in diabetes: pathogenesis, significance, and treatment. Review of Diabetic Studies 10 133-156. (doi:10.1900/RDS.2013.10.133)

Hink U, Li H, Mollnau H, Oelze M, Matheis E, Hartmann M, Skatchkov M, Thaiss F, Stahl RA, Warnholtz A et al. 2001 Mechanisms underlying endothelial dysfunction in diabetes mellitus. Circulation Research 13 E14-E22. (doi:10.1161/01.RES.88.2.e14)

Holvoet P, De Keyzer D \& Jacobs DR 2008 Oxidized LDL and the metabolic syndrome. Future Lipidology 3 637-649. (doi:10.2217/17460875.3.6.637)

Hudacko RM, Sciancalepore JP \& Fyfe BS 2009 Diabetic microangiopathy in the liver: an autopsy study of incidence and association with other diabetic complications. American Journal of Clinical Pathology 132 494-499. (doi:10.1309/AJCPQBFF42ZZXXRQ)

Ishino S, Mukai T, Kume N, Asano D, Ogawa M, Kuge Y, Minami M, Kita T, Shiomi M \& Saji H 2007 Lectin-like oxidized LDL receptor-1 (LOX-1) expression is associated with atherosclerotic plaque instability-analysis in hypercholesterolemic rabbits. Atherosclerosis 195 48-56. (doi:10.1016/j.atherosclerosis.2006.11.031)

Kalani M 2008 The importance of endothelin-1 for microvascular dysfunction in diabetes. Vascular Health and Risk Management 4 1061-1068.

Kauser K, da Cunha V, Fitch R, Mallari C \& Rubanyi GM 2000 Role of endogenous nitric oxide in progression of atherosclerosis in apolipoprotein E-deficient mice. American Journal of Physiology. Heart and Circulatory Physiology 278 H1679-H1685.

Kohan DE, Rossi NF, Inscho EW \& Pollock DM 2011 Regulation of blood pressure and salt homeostasis by endothelin. Physiological Reviews 91 71-77. (doi:10.1152/physrev.00060.2009)

Krishnan B, Babu S, Walker J, Walker AB \& Pappachan JM 2013 Gastrointestinal complications of diabetes mellitus. World Journal of Diabetes 4 51-63. (doi:10.4239/wjd.v4.i3.51)

Le Couteur DG, Fraser R, Cogger VC \& McLean AJ 2002 Hepatic pseudocapillarisation and atherosclerosis in ageing. Lancet 359 1612-1615. (doi:10.1016/S0140-6736(02)08524-0)

Li D \& Mehta JL 2000 Upregulation of endothelial receptor for oxidized LDL (LOX-1) by oxidized LDL and implications in apoptosis of human coronary artery endothelial cells: evidence from use of antisense LOX-1 mRNA and chemical inhibitors. Arteriosclerosis, Thrombosis, and Vascular Biology 20 1116-1122. (doi:10.1161/01.ATV.20.4.1116)

Li L, Chu Y, Fink GD, Engelhardt JF, Heistad DD \& Chen AF 2003 Endothelin-1 stimulates arterial VCAM-1 expression via NADPH oxidase-derived superoxide in mineralocorticoid hypertension. Hypertension 42 (5) 997-1003. (doi:10.1161/01.HYP.0000095980.43859.59)

Li R, Oteiza A, Sørensen KK, McCourt P, Olsen R, Smedsrød B \& Svistounov D 2011 Role of liver sinusoidal endothelial cells and stabilins in elimination of oxidized low-density lipoproteins. American Journal of Physiology. Gastrointestinal and Liver Physiology 300 71-81. (doi:10.1152/ajpgi.00215.2010)

Little PJ, Ivey ME \& Osman N 2008 Endothelin-1 actions on vascular smooth muscle cell functions as a target for the prevention of atherosclerosis. Current Vascular Pharmacology 6 195-203. (doi:10.2174/157016108784911966)

Lopes-Virella MF, Virella G, Orchard TJ, Koskinen S, Evans RW, Becker DJ \& Forrest KY 1999 Antibodies to oxidized LDL and LDL-containing immune complexes as risk factors for coronary artery disease in diabetes mellitus. Clinical Immunology 90 165-172. (doi:10.1006/clim.1998.4631)

Lv WS, Sun RX, Gao YY, Wen JP, Pan RF, Li L, Wang J, Xian YX, Cao CX \& Zheng M 2013 Nonalcoholic fatty liver disease and microvascular complications in type 2 diabetes. World Journal of Gastroenterology 19 3134-3142. (doi:10.3748/wjg.v19.i20.3134)

Ma Y, Liu J, Li P, Zhu S \& Lin C 2012 Effects of serum containing Tanyu Tongzhi formula on production of NO, caveolin-1 and eNOS in HUVECs injured by ox-LDL. Zhongguo Zhong Yao Za Zhi 37 974-978.
Maziere C, Auclair M, Djavaheri-Mergny M, Packer L \& Maziere JC 1996 Oxidized low density lipoprotein induces activation of the transcription factor NFKB in fibroblasts, endothelial and smooth muscle cells. IUBMB Life 39 1201-1207. (doi:10.1080/15216549600201392)

McCuskey RS 2006 Sinusoidal endothelial cells as an early target for hepatic toxicants. Clinical Hemorheology and Microcirculation 34 5-10.

Mehta JL, Chen J, Hermonat PL, Romeo F \& Novelli G 2006 Lectin-like, oxidized low-density lipoprotein receptor-1 (LOX-1): a critical player in the development of atherosclerosis and related disorders. Cardiovascular Research 69 4536-4544. (doi:10.1016/j.cardiores.2005.09.006)

Mehta JL, Sanada N, Hu CP, Chen J, Dandapat A, Sugawara F, Satoh H, Inoue K, Kawase Y, Jishage K et al. 2007 Deletion of LOX-1 reduces atherogenesis in LDLR knockout mice fed high cholesterol diet. Circulation Research 100 1634-1642. (doi:10.1161/CIRCRESAHA. 107.149724)

Mertens A \& Holvoet P 2011 Oxidized LDL and HDL:antagonists in atherothrombosis. FASEB Journal 15 2073-2084. (doi:10.1096/ fj.01-0273rev)

Mohamed MR \& McFadden G 2009 NFкB inhibitors: strategies from poxviruses. Cell Cycle 8 3125-3132. (doi:10.4161/cc.8.19.9683)

Morawietz H, Duerrschmidt N, Niemann B, Galle J, Sawamura T \& Holtz J 2001 Induction of the oxLDL receptor LOX-1 by endothelin-1 in human endothelial cells. Biochemical and Biophysical Research Communications 284 (4) 961-965. (doi:10.1006/bbrc.2001.5044)

Morawietz H, Duerrschmidt N, Niemann B, Galle J, Sawamura T \& Holtz J 2002 Augmented endothelial uptake of oxidized low-density lipoprotein in response to endothelin-1. Clinical Science 103 (Suppl 48) 9-12.

Ogi M, Yokomori H, Oda M, Yoshimura K, Nomura M, Ohshima S, Akita M, Toda K \& Ishii H 2003 Distribution and localization of caveolin-1 in sinusoidal cells in rat liver. Medical Electron Microscopy 36 33-40. (doi:10.1007/s007950300004)

Oishi P, Azakie A, Harmon C, Fitzgerald RK, Grobe A, Xu J, Hendricks-Munoz K, Black SM \& Fineman JR 2006 Nitric oxideendothelin-1 interactions after surgically induced acute increases in pulmonary blood flow in intact lambs. American Journal of Physiology. Heart and Circulatory Physiology 290 1922-1932. (doi:10.1152/ajpheart. 01091.2005)

Oteiza A, Li R, McCuskey RS, Smedsrød B \& Sørensen KK 2011 Effects of oxidized low-density lipoproteins on the hepatic microvasculature. American Journal of Physiology. Gastrointestinal and Liver Physiology $\mathbf{3 0 1}$ 684-693. (doi:10.1152/ajpgi.00347)

Pasarín M, La Mura V, Gracia-Sancho J, García-Calderó H, RodríguezVilarrupla A, García-Pagán JC, Bosch J \& Abraldes JG 2012 Sinusoidal endothelial dysfunction precedes inflammation and fibrosis in a model of NAFLD. PLoS ONE 7 e32785. (doi:10.1371/journal.pone.0032785)

Pirillo A, Norata GD \& Catapano AL 2013 LOX-1, OxLDL, and atherosclerosis. Mediators of Inflammation 2013 152786. (doi:10.1155/ 2013/152786)

Rautureau Y \& Schiffrin EL 2012 Endothelin in hypertension: an update. Current Opinion in Nephrology and Hypertension 21 128-136. (doi:10.1097/MNH.0b013e32834f0092)

Renier G, Maingrette F \& Li L 2007 Diabetic vasculopathy and the lectinlike oxidized low-density lipoprotein receptor-1 (LOX-1). Current Diabetes Reviews 3 103-110. (doi:10.2174/157339907780598225)

Sawamura T, Kume N, Aoyama T, Moriwaki H, Hoshikawa H, Aiba Y, Tanaka T, Miwa S, Katsura Y, Kita T et al. 1997 An endothelial receptor for oxidized low-density lipoprotein. Nature 386 73-77. (doi:10.1038/ 386073a0)

Steinberg D 1997 Low density lipoprotein oxidation and its pathobiological significance. Journal of Biological Chemistry 272 20963-20966. (doi:10.1074/jbc.272.34.20963)

Sun SW, Zu XY, Tuo QH, Chen LX, Lei XY, Li K, Tang CK \& Liao DF 2010 Caveolae and caveolin-1 mediate endocytosis and transcytosis of oxidized low density lipoprotein in endothelial cells. Acta Pharmacologica Sinica 31 1336-1342. (doi:10.1038/aps.2010.87) http://jme.endocrinology-journals.org DOI: 10.1530/JME-14-0049
() 2014 Society for Endocrinology Printed in Great Britain 
Truong TQ, Brodeur MR, Falstrault L, Rhainds D \& Brissette L 2009 Expression of caveolin-1 in hepatic cells increases oxidized LDL uptake and preserves the expression of lipoprotein receptors. Journal of Cellular Biochemistry 108 906-915. (doi:10.1002/jcb.22321)

Venkatraman L \& Tucker-Kellogg L 2013 The CD47-binding peptide of thrombospondin-1 induces defenestration of liver sinusoidal endothelial cells. Liver International 33 1386-1397. (doi:10.1111/liv.12231)

Walenbergh SM, Koek GH, Bieghs V \& Shiri-Sverdlov R 2013 Non-alcoholic steatohepatitis: the role of oxidized low-density lipoproteins. Hepatology 58 801-810. (doi:10.1016/j.jhep.2012.11.014)

Wang BY, Ju XH, Fu BY, Zhang J \& Cao YX 2005 Effects of ethanol on liver sinusoidal endothelial cells-fenestrae of rats. Hepatobiliary \& Pancreatic Diseases International 4 422-426.

Witztum JL \& Steinberg D 2001 The oxidative modification hypothesis of atherosclerosis: does it hold forhumans? Trends in Cardiovascular Medicine 11 93-102. (doi:10.1016/S1050-1738(01)00111-6)

Wohlfart P, Xu H, Endlich A, Habermeier A, Closs EI, Hübschle T, Mang C, Strobel H, Suzuki T, Kleinert $\mathrm{H}$ et al. 2008 Antiatherosclerotic effects of small-molecular-weight compounds enhancing endothelial nitricoxide synthase (eNOS) expression and preventing eNOS uncoupling. Journal of Phamacology and Experimental Therapeutics 325 370-379. (doi:10.1124/jpet.107.128009)

Wu CC, Wang SH, Kuan II, Tseng WK, Chen MF, Wu JC \& Chen YL 2009 OxLDL upregulates caveolin-1 expression in macrophages: role for caveolin-1 in the adhesion of oxLDL-treated macrophages to endothelium. Journal of Cellular Biochemistry 107 460-472. (doi:10.1002/jcb.22144)

Xu S, Ogura S, Chen J, Little PJ, Moss J \& Liu P 2013 LOX-1 in atherosclerosis: biological functions and pharmacological modifiers. Cellular and Molecular Life Sciences 70 2859-2872. (doi:10.1007/ s00018-012-1194-z)
Yokomori H, Yoshimura K, Ohshima S, Nagai T, Fujimaki K, Nomura M, Oda M \& Hibi T 2006 The endothelin-1 receptor-mediated pathway is not involved in the endothelin-1-induced defenestration of liver sinusoidal endothelial cells. Liver International 26 1268-1276. (doi:10.1111/j.1478-3231.2006.01365.x)

Yokomori H, Oda M, Yoshimura K, Nagai T, Fujimaki K, Watanabe S \& Hibi T 2009 Caveolin-1 and Rac regulate endothelial capillary-like tubular formation and fenestral contraction in sinusoidal endothelial cells. Liver International 29 266-276. (doi:10.1111/j.1478-3231.2008.01891.x)

Yokomori H, Oda M, Yoshimura K \& Hibi T 2012 Recent advances in liver sinusoidal endothelial ultrastructure and fine structure immunocytochemistry. Micron 43 129-134. (doi:10.1016/j.micron.2011.08.002)

Yoshimoto R, Fujita Y, Kakino A, Iwamoto S, Takaya T \& Sawamura T 2011 The discovery of LOX-1, its ligands and clinical significance. Cardiovascular Drugs and Therapy 25 379-391. (doi:10.1007/ s10557-011-6324-6)

Zabirnyk O, Liu W, Khalil S, Sharma A \& Phang JM 2010 Oxidized low-density lipoproteins upregulate proline oxidase to initiate ROS-dependent autophagy. Carcinogenesis 31 446-454. (doi:10.1093/carcin/bgp299)

Zhou J, Jia WP, Bao YQ, Ma XJ, Lu W, Yu M, Pan JM, Hu C \& Xiang KS 2007 Study on prevalence and risk factors of fatty liver of patients with type 2 diabetes. Zhonghua Yi Xue Za Zhi 87 2249-2252.

Zhou J, Abid MD, Xiong Y \& Chen Q 2013 Ox-LDL downregulates eNOS activity via LOX-1-mediated endoplasmic reticulum stress. International Journal of Molecular Medicine 32 1442-1450. (doi:10.3892/ijmm.2013. 1513)

Zmijewski JW, Moellering DR, Le Goffe C, Landar A, Ramachandran A \& Darley-Usmar VM 2005 Oxidized LDL induces mitochondrially associated reactive oxygen/nitrogen species formation in endothelial cells. American Journal of Physiology. Heart and Circulatory Physiology 289 H852-H861. (doi:10.1152/ajpheart.00015.2005)

Received in final form 14 July 2014

Accepted 23 July 2014

Accepted Preprint published online 23 July 2014
() 2014 Society for Endocrinology Printed in Great Britain 